\title{
BMJ Open Reducing the default dispense quantity for new opioid analgesic prescriptions: study protocol for a cluster randomised controlled trial
}

\author{
Marcus A Bachhuber, ${ }^{1}$ Denis Nash, ${ }^{2,3}$ William N Southern, ${ }^{4}$ Moonseong Heo, ${ }^{5}$ \\ Matthew Berger, ${ }^{4,6}$ Mark Schepis, ${ }^{6}$ Chinazo O Cunningham ${ }^{1}$
}

To cite: Bachhuber MA, Nash D, Southern WN, et al. Reducing the default dispense quantity for new opioid analgesic prescriptions: study protocol for a cluster randomised controlled trial. BMJ Open 2018;8:e019559. doi:10.1136/ bmjopen-2017-019559

- Prepublication history for this paper is available online. To view these files, please visit the journal online (http://dx.doi org/10.1136/bmjopen-2017019559).

Received 11 September 2017 Revised 15 February 2018 Accepted 19 March 2018
Check for updates

For numbered affiliations see end of article.

Correspondence to Dr Marcus A Bachhuber; marcus.bachhuber@gmail.com

\section{ABSTRACT}

Introduction As opioid analgesic consumption has grown, so have opioid use disorder and opioid-related overdoses. Reducing the quantity of opioid analgesics prescribed for acute non-cancer pain can potentially reduce risks to the individual receiving the prescription and to others who might unintentionally or intentionally consume any leftover tablets. Reducing the default dispense quantity for new opioid analgesic prescriptions in the electronic health record (EHR) is a promising intervention to reduce prescribing.

Methods and analysis This study is a prospective cluster randomised controlled trial with two parallel arms. Primary care sites $(n=32)$ and emergency departments $(n=4)$ will be randomised in matched pairs to either a modification of the EHR so that new opioid analgesic prescriptions default to a dispense quantity of 10 tablets (intervention) or to no EHR change (control). The dispense quantity will remain fully modifiable by providers in both arms. From 6 months preintervention to 18 months postintervention, patient-level data will be analysed (ie, the patient is the unit of inference). Patient eligibility criteria are: $(A)$ received a new opioid analgesic prescription, defined as no other opioid analgesic prescription in the prior 6 months; (B) age $\geq 18$ years; and (C) no cancer diagnosis within 1 year prior to the new opioid analgesic prescription. The primary outcome will be the quantity of opioid analgesics prescribed in the initial prescription. Secondary outcomes will include opioid analgesic reorders and health service utilisation within 30 days after the initial prescription. Outcomes will be compared between study arms using a difference-in-differences analysis.

Ethics and dissemination This study has been approved by the Montefiore Medical Center/Albert Einstein College of Medicine Institutional Review Board with a waiver of informed consent (2016-6036) and is registered on ClinicalTrials.gov (NCT03003832, 6 December 2016). Findings will be disseminated through publication, conferences and meetings with health system leaders. Trial registration number NCT03003832; Pre-results.

\section{INTRODUCTION}

In the USA, opioid consumption, opioid use disorder and fatal overdoses involving opioids have increased rapidly. Between 1999 and
Strengths and limitations of this study

- Reducing the default dispense quantity for new opioid analgesic prescriptions in the electronic health record is a novel intervention with the potential for widespread implementation and scale-up.

- A cluster randomised controlled trial will provide rigorous evidence for or against efficacy.

- Consideration of unintended consequences such as prescription reorders and increased health service utilisation will provide additional information on the impact of the intervention

- The setting of the trial (a single urban medical centre, with multiple, diverse clinics) may limit generalisability.

- Lack of access to data (ie, prescriptions and visits) at outside institutions may lead to measurement error for some outcomes.

2015, sales of opioid analgesics tripled. ${ }^{1}$ In 2015, 33091 individuals died of a drug overdose involving opioids. ${ }^{2}$ Beyond the human cost, the economic cost of opioid use disorder and overdose is estimated to be almost US $\$ 80$ billion (2015 US\$) annually. ${ }^{3}$

While most research aiming to reduce morbidity and mortality from opioid analgesics focuses on people with chronic pain, opioid analgesics for acute non-cancer pain are also associated with significant personal and public health risk. Fatal and non-fatal overdoses occur among people with new or short-term opioid analgesic prescriptions. ${ }^{45}$ Furthermore, up to $72 \%$ of people prescribed opioid analgesics have tablets left over, and most plan to keep them. ${ }^{6-8}$ Leftover tablets are often misused, diverted or accidentally ingested by household members (eg, children) and are a contributor to overdose mortality beyond the index patient. ${ }^{9-13}$ Previous interventions to reduce opioid analgesic prescribing for acute pain have included provider education or 
promulgation of guidelines; however, these interventions can be labour intensive and may only have shortlived effects. In addition, as of December 2017, at least 24 states have passed laws setting limits on opioid analgesic prescriptions ${ }^{14}$; however, enforcement mechanisms are often unclear and the impact of such laws on prescribing is not known.

Environmental or structural interventions, such as modifying default prescribing options, have the potential to change provider behaviour. Defaults can have powerful effects, including in healthcare settings. ${ }^{15}$ For opioid analgesic prescriptions, this would take the form of reducing the default dispense quantity (ie, the default number of tablets to dispense) for all new prescriptions. While providers can modify the number of tablets actually prescribed, default options can alter practice. For example, within the electronic health record (EHR), changing prescription defaults from brand name to generic increased generic prescribing significantly. ${ }^{16}$ In one recent study involving opioid analgesics, removing the existing default dispense quantity for two types of opioid analgesics was associated with a modestly higher mean number of tablets dispensed and an increase in the variability of prescriptions, relative to preintervention. ${ }^{17}$ While these studies suggest that defaults can alter opioid analgesic prescribing behaviour, the impact of reducing the default dispense quantity to encourage reductions in opioid analgesic prescribing has not been rigorously studied.

While reducing the default dispense quantity for new opioid analgesic prescriptions has the potential to reduce the quantity prescribed for acute pain, any reduction may be offset, at least in part, by the potential for unintended consequences. These can include an increased need for prescription reorders, medical visits due to inadequately treated pain, or both. However, the large proportion of patients with leftover opioid analgesic tablets suggests that reductions in the quantity prescribed will simply move towards aligning prescriptions with what patients actually take for the acute episode of pain. ${ }^{6-8}$

The goal of this study is to investigate the impact of a uniform, reduced, default dispense quantity for new opioid analgesic prescriptions on the quantity prescribed for acute pain. We will test this intervention in a cluster randomised controlled trial in 32 primary care sites and four emergency departments (ED), responsible for over 13000 new opioid analgesic prescriptions annually. We hypothesise that, compared with control, reducing the default dispense quantity will lead to a higher percentage of prescriptions written for the new, reduced default number of tablets or fewer. In addition, compared with control, we hypothesise that reducing the default dispense quantity will not lead to a significant increase in opioid analgesic prescription reorders or primary care visits, ED visits or hospitalisations.
METHODS AND ANALYSIS

\section{Study setting}

Montefiore Medical Center (Montefiore) is the largest healthcare system in The Bronx (a borough of New York City) and provides comprehensive primary, specialty, surgical and emergency care at 4 hospitals, 4 EDs and over 40 ambulatory clinics, with over 3 million patient visits annually. Montefiore is also a major integrated healthcare delivery system, administering federal (ie, managed Medicaid and Medicare) and private insurance plans and coordinating care for approximately 225000 individuals. For this study, we have selected the ambulatory settings in which opioid analgesic prescribing is common: primary care practices and EDs.

\section{Eligibility criteria}

\section{Primary care and ED sites}

We will include all primary care $(n=32)$ and $(n=4)$ ED sites within Montefiore. Primary care sites can be designated as internal medicine, family medicine or urgent care.

\section{Provider participants}

As the intervention is a modification to the EHR, the primary participants are Montefiore providers. Eligible providers will include those who provide adult primary care or ED care.

\section{Patient participants}

We will analyse outcomes for patients who: (A) received a new opioid analgesic prescription, defined as no other opioid analgesic prescription of any type in the preceding 6 months (a definition used in previous cohort studies) $)^{1819}$; (b) aged $\geq 18$ years; and $(\mathrm{C})$ no International Classification of Diseases, 10th Revision, Clinical Modification (ICD-10-CM) diagnosis code for cancer within 1 year prior to the new opioid analgesic prescription. For patients receiving more than one new opioid analgesic prescription during the study period, we will only include the first prescription.

\section{Intervention and control conditions}

The intervention condition is a site-level change to the EHR to implement a uniform, reduced, default dispense quantity for new opioid analgesic prescriptions. The number of tablets actually prescribed will be fully modifiable by providers who can tailor the prescription based on clinical factors. The intervention will include all shortacting opioid analgesics commonly used to treat acute pain: immediate-release oxycodone, immediate-release hydrocodone, tramadol and codeine. We will include all brand and generic formulations and all tablet strengths and coformulations with acetaminophen.

We have chosen 10 tablets as the default dispense quantity for all medication products included in the intervention condition. For opioid analgesics, there are no specific studies addressing the optimal quantity that minimises the risks of harms while adequately treating pain. Generally, guidelines recommend a limited duration with early reassessment. ${ }^{20-22}$ While medications 
included in the intervention are typically written for a range of one to two tablets every 4-6hours, as needed, patients may only take between one and three tablets per day total. ${ }^{23-25}$ We chose a default of 10 tablets because we believe it represents at least a 3-5 day supply for most patients.

The usual EHR will serve as the control condition. Depending on the exact medication product, the pre-existing default number of tablets is typically 30 or blank, with several outliers (table 1). These pre-existing defaults are a mixture of those preloaded in the base installation of our EHR and those created by our institution when generating defaults for commonly prescribed medications. While most products have a pre-existing default, some do not (ie, the 'quantity dispensed' field is blank). Therefore, while the intervention will reduce the default dispense quantity for most products, it will create a default dispense quantity for some.

\section{Outcomes}

To determine the impact of the intervention, we will analyse patient-level outcomes. Therefore, the unit of inference is the patient. We will collect outcome data from 6 months prior to intervention implementation to 18 months after implementation.

\section{Primary outcome}

Quantity of opioid analgesics. This outcome refers to the quantity prescribed in each new opioid analgesic prescription. We will use three measures of the primary outcome:

1. $\leq 10$ tablets (primary measure, dichotomous). We will classify all prescriptions as greater than or less than/equal to 10 tablets (the default). This outcome is relevant specifically to the impact of the intervention.

2. Number of tablets to dispense (continuous). This outcome is relevant to accidental ingestion and diversion (ie, the number of tablets available for consumption).

3. Total morphine milligram equivalents (MME) to dispense (continuous). The use of MME standardises comparisons between different types of opioid analgesics with different strengths and potencies. ${ }^{26}$ Overdose risk increases with increasing $\mathrm{MME}^{42728}$ so this measure is relevant to overdose risk.

\section{Secondary outcomes}

1. Opioid analgesic prescription reorders within 30 days of the initial prescription. Such reorders can occur if patients do not receive an adequate supply of opioid analgesics to treat their pain in the initial prescription and contact their providers to obtain more. Measured as: (A) any reorder $(y / n)$; (B) number of tablets; and (C) MME.

2. Health service utilisation within 30 days of the initial prescription. Medical visits can occur if patients experience an opioid-related adverse event (eg, delirium) or intractable pain (eg, from not enough medication). We will analyse primary care visits, ED visits and hospitalisations for any reason.

\section{Provider and patient characteristics (covariates)}

In addition to primary and secondary outcomes, we will collect additional data on providers and patients. We have selected variables that are likely to be confounders. For providers, we will collect sex and years since graduation from medical school. For patients, we will collect demographic information (age, sex and race/ethnicity as recorded in the EHR). We will also collect the pain diagnosis at the visit where the initial opioid analgesic was prescribed (ie, the indication for the opioid analgesic) in addition to the presence or absence of a history of psychiatric illness and a history of substance use disorder within the 1 year preceding the initial opioid analgesic prescription. For pain diagnoses, we will group ICD-10-CM diagnosis codes into clinically meaningful categories based on the diagnostic categories outlined in the US Department of Health and Human Services National Pain Strategy. ${ }^{29}$ For history of psychiatric illness and history of substance use disorder, we will use existing diagnosis code groupings produced by the Healthcare Cost and Utilization Project, sponsored by the Agency for Healthcare Research and Quality of the US Department of Health and Human Services. ${ }^{30}$

\section{Randomisation}

The unit of randomisation will be the site (ie, cluster randomisation). Compared with randomisation at the level of the provider (ie, individual-level randomisation), randomisation of sites would be expected to reduce statistical efficiency due to correlated outcomes within clusters. ${ }^{31}$ However, we chose site-level randomisation instead of provider-level randomisation to reduce contamination and to potentially increase the intervention's effectiveness via peer effects. ${ }^{32} 33$ At Montefiore, the vast majority of providers only practise at one site. In addition, technical limitations of Montefiore's EHR (Epic) render provider-level randomisation less feasible.

Study sites differ greatly in visit volume and characteristics; therefore, we will randomise in matched pairs to avoid a major imbalance which could threaten study validity. For randomisation, we will stratify sites by type (ie, primary care vs ED). Further, within primary care sites, prescribing patterns and the intervention's impact may differ by specialty (ie, internal medicine and family medicine) and whether the site is a training site for resident physicians. Therefore, we will stratify on these variables as well. Within strata, we will use optimal non-bipartite matching to pair sites based on the number of new opioid analgesic prescriptions, the number of visits and the percentage of patients with commercial insurance. ${ }^{34}$ For ED sites, given the very large differences in visit volume, we will divide the four sites into a 'pair' consisting of the largest ED versus the three other smaller EDs combined.

\section{Blinding}

Randomisation of sites within pairs will be conducted by the study statistician and provided directly to the health information technology department. Other study 
Table 1 Pre-existing default dispense quantity for short-acting opioid analgesics included in the intervention*

\begin{tabular}{|c|c|c|c|}
\hline Opioid ingredient & Product name and strength & Primary care sites & Emergency department sites \\
\hline \multirow[t]{21}{*}{ Oxycodone } & Oxycodone $5 \mathrm{mg}$ tablet & 30 & 30 \\
\hline & Oxycodone $5 \mathrm{mg}$ capsule & 30 & 30 \\
\hline & Oxycodone $10 \mathrm{mg}$ tablet & Blank & Blank \\
\hline & Oxycodone $15 \mathrm{mg}$ tablet & 30 & 30 \\
\hline & Oxycodone $20 \mathrm{mg}$ tablet & Blank & Blank \\
\hline & Oxycodone $30 \mathrm{mg}$ tablet & 30 & 30 \\
\hline & Roxicodone $5 \mathrm{mg}$ tablet & 20 & 20 \\
\hline & Roxicodone $15 \mathrm{mg}$ tablet & 30 & 30 \\
\hline & Roxicodone $30 \mathrm{mg}$ tablet & 30 & 30 \\
\hline & Oxycodone-acetaminophen $2.5 \mathrm{mg}-325 \mathrm{mg}$ tablet & 30 & 30 \\
\hline & Oxycodone-acetaminophen $5 \mathrm{mg}-325 \mathrm{mg}$ tablet & Blank & Blank \\
\hline & Oxycodone-acetaminophen $7.5 \mathrm{mg}-325 \mathrm{mg}$ tablet & 30 & 30 \\
\hline & Oxycodone-acetaminophen $10 \mathrm{mg}-325 \mathrm{mg}$ tablet & 30 & 30 \\
\hline & Percocet $2.5 \mathrm{mg}-325 \mathrm{mg}$ tablet & 30 & 30 \\
\hline & Percocet $5 \mathrm{mg}-325 \mathrm{mg}$ tablet & Blank & Blank \\
\hline & Percocet $7.5 \mathrm{mg}-325 \mathrm{mg}$ tablet & 20 & 20 \\
\hline & Percocet $10 \mathrm{mg}-325 \mathrm{mg}$ tablet & 20 & 20 \\
\hline & Endocet $2.5 \mathrm{mg}-325 \mathrm{mg}$ tablet & 30 & 30 \\
\hline & Endocet $5 \mathrm{mg}-325 \mathrm{mg}$ tablet & Blank & Blank \\
\hline & Endocet $7.5 \mathrm{mg}-325 \mathrm{mg}$ tablet & 30 & 30 \\
\hline & Endocet $10 \mathrm{mg}-325 \mathrm{mg}$ tablet & 30 & 30 \\
\hline \multirow[t]{12}{*}{ Hydrocodone } & Hydrocodone-acetaminophen $5 \mathrm{mg}-300 \mathrm{mg}$ tablet & 112 & 112 \\
\hline & Hydrocodone-acetaminophen $5 \mathrm{mg}-325 \mathrm{mg}$ tablet & 50 & 30 \\
\hline & Hydrocodone-acetaminophen $7.5 \mathrm{mg}-300 \mathrm{mg}$ tablet & 180 & 180 \\
\hline & Hydrocodone-acetaminophen $7.5 \mathrm{mg}-325 \mathrm{mg}$ tablet & 50 & 30 \\
\hline & Hydrocodone-acetaminophen $10 \mathrm{mg}-300 \mathrm{mg}$ tablet & 180 & 180 \\
\hline & Hydrocodone-acetaminophen $10 \mathrm{mg}-325 \mathrm{mg}$ tablet & 30 & 30 \\
\hline & Lortab $5 \mathrm{mg}-325 \mathrm{mg}$ tablet & 30 & 30 \\
\hline & Lortab $7.5 \mathrm{mg}-325 \mathrm{mg}$ tablet & 30 & 30 \\
\hline & Lortab $10 \mathrm{mg}-325 \mathrm{mg}$ tablet & 30 & 30 \\
\hline & Norco $5 \mathrm{mg}-325 \mathrm{mg}$ tablet & 30 & 30 \\
\hline & Norco $7.5 \mathrm{mg}-325 \mathrm{mg}$ tablet & 30 & 30 \\
\hline & Norco $10 \mathrm{mg}-325 \mathrm{mg}$ tablet & 30 & 30 \\
\hline \multirow[t]{4}{*}{ Tramadol } & Tramadol $50 \mathrm{mg}$ tablet & Blank & Blank \\
\hline & Ultram $50 \mathrm{mg}$ tablet & 90 & 20 \\
\hline & Tramadol-acetaminophen 37.5 mg-325 mg tablet & 30 & 30 \\
\hline & Ultracet $37.5 \mathrm{mg}-325 \mathrm{mg}$ tablet & 30 & 30 \\
\hline \multirow[t]{7}{*}{ Codeine } & Codeine sulfate $15 \mathrm{mg}$ tablet & 30 & 30 \\
\hline & Codeine sulfate $30 \mathrm{mg}$ tablet & 30 & 30 \\
\hline & Acetaminophen-codeine $300-15 \mathrm{mg}$ tablet & 30 & 30 \\
\hline & Acetaminophen-codeine $300-30 \mathrm{mg}$ tablet & Blank & 15 \\
\hline & Acetaminophen-codeine $300-60 \mathrm{mg}$ tablet & 30 & 30 \\
\hline & Tylenol/codeine \#3 300-30 mg tablet & Blank & Blank \\
\hline & Tylenol/codeine \#4 300-60 mg tablet & 30 & 30 \\
\hline
\end{tabular}

*Pre-existing defaults are a mixture of those preloaded in the base installation of the electronic health record system and those created by our institution when generating defaults for commonly prescribed medications. 
investigators will therefore be blind to randomisation assignment.

\section{Data collection and management}

We will obtain provider data from our institution's internal provider directory as well as publicly accessible medical license data from New York State. We will obtain all patient data from Montefiore's EHR. Study data will be stored in an encrypted, password-protected database only accessible to study investigators.

\section{Statistical analysis}

We will conduct analyses at two time points, 6 months after intervention implementation and 18 months after intervention implementation. Using a difference-in-differences (DID) analysis, we will determine the impact of the intervention by comparing the change in outcomes in the intervention group with the change in outcomes in the control group. ${ }^{35}$ For example, for the 6-month analysis, we will compare the change in the intervention group's outcomes from -6 months to +6 months to the change in the control group's outcomes from -6 months to +6 months.

A DID analysis has advantages. First, while we can include covariates to adjust for imbalance in site, provider and patient characteristics between intervention and control groups, DID accounts for residual time-invariant group-level heterogeneity such as differences in baseline outcome levels and hard-to-measure factors like overall quality of care between intervention and control sites. ${ }^{36}$ Second, DID will allow us to account for prescribing changes due to factors other than the intervention (eg, state or city policies aimed at reducing prescribing). For example, in July 2016, New York State enacted a law limiting opioid analgesic prescriptions for acute pain to a 7-day supply.

A DID analysis also relies on several assumptions which we will examine. ${ }^{36}$ First, we will assess whether trends in outcomes were parallel between the intervention and control sites prior to the intervention. For this analysis, in the preintervention period, we will determine the significance of an interaction term between study allocation (intervention/control) and month. Second, to determine the composition of the intervention and the control sites, we will calculate and report descriptive statistics for both provider and patient characteristics, preintervention and postintervention. Finally, we will examine the potential for contamination of the arms. Although we expect the number of providers who write prescriptions at both an intervention and a control site will be low, we will determine the number of such providers and report it.

We will conduct the main DID analysis using generalised linear mixed regression models. We will include a variable indicating time (preintervention/postintervention) and a variable indicating study allocation (intervention/control). In DID, the interaction of these two variables is the parameter of interest. To adjust for potential changes in composition over time, we will include relevant site characteristics (number of new opioid analgesic prescriptions, the number of visits and percentage of patients with commercial insurance), provider characteristics (sex and years since medical school graduation) and patient characteristics (age, sex, race/ethnicity, pain diagnosis, history of substance use disorder, history of psychiatric disorder) as covariates in all models. To account for the nesting of patients within providers and providers within sites, we will include random intercepts both at the provider level and at the matched site pair level. For all estimates, we will calculate heteroscedasticity robust (empirical) SEs. ${ }^{38} 39$

For each outcome, we will explore the distribution of the outcome variable and potential transformations to determine the appropriate regression models (eg, binomial, linear, Poisson or negative binomial). When analysing the impact of the intervention at 18 months, we will identify any change in the intervention's impact after 6 months (ie, whether it decays over time) by using the 0-6 month postintervention period as the referent.

In addition to the main analysis, we will conduct several exploratory subgroup analyses. We will analyse the impact of the intervention stratified by site type (ie, primary care vs ED) and by medication type (eg, schedule II vs schedules III and IV). We will also perform separate analyses on products where the pre-existing default was reduced and products where there was no pre-existing default (ie, the pre-existing 'quantity dispensed' field was blank).

Finally, we intend to explore other analyses examining the precise timing of any changes in outcomes (eg, immediate or delayed) and to characterise the heterogeneity of the intervention's effect between matched pairs. Such analyses will be defined post hoc and are subject to availability of resources such as additional statistical support and technical considerations such as convergence of relevant statistical models.

\section{Sample size}

From preliminary data analyses, we estimate eligible providers $(\mathrm{n}=\sim 17$ per site) will write a total of approximately 7000 new opioid analgesic prescriptions $(n=\sim 11$ prescriptions per provider) from the 36 sites during a 6-month postintervention period. And, in the baseline period (ie, 6 months prior), $32.7 \%$ of prescriptions will be for $\leq 10$ tablets. From these parameters, we estimated the minimal detectable difference between study arms using a three-level hierarchical model (ie, patients clustered within providers who are clustered within matched site pairs). Because the intracluster correlation coefficient (ICC) is not known, we used a range of ICC from 0.01 to 0.1 at the patient level; only this level of ICC is needed for power analysis under our study design. ${ }^{40}$ Because any change in outcomes in the control arm is also unknown, we used a range of increases in the percentage of prescriptions for $\leq 10$ tablets in the control arm of $0-10$ percentage points. Within this range of ICC, change in control arm outcomes, alpha $=0.05$ and power $\geq 80 \%$, this study will be powered to detect a change in the intervention arm, 
over and above any change in the control arm, of 4.4-4.7 percentage points.

\section{Timeline and monitoring}

We randomised sites and implemented the new default dispense quantity for the intervention arm on 13 December 2016. Before this change, primary care sites had the same EHR for approximately 19 months. Two ED sites had the same EHR for 11 months and two ED sites had the same EHR system for 7 months (ie, those sites implemented the current EHR just before start of the 6-month preintervention period).

The principal investigator $(\mathrm{MBa})$ will oversee data and safety monitoring, including review of any protocol deviations (eg, unplanned changes to the EHR) and submission of an annual progress report to the Montefiore Medical Center/Albert Einstein College of Medicine Institutional Review Board and the study funder (The National Institute on Drug Abuse of the National Institutes of Health). As this study evaluates an EHR modification using data collected directly from the EHR, study investigators will not have direct contact with any human subjects. Because of the low-risk nature of the intervention, we will not convene a formal Data Safety and Monitoring Board and will not conduct planned audits.

\section{Limitations}

This study has limitations. First, we will only able to obtain data from within our medical centre, outside prescriptions and visits will not be captured. Therefore, we may underestimate the number of opioid analgesic reorders and the degree of health service utilisation. Further, this may bias the study findings if patients in one arm are more likely to obtain follow-up care at Montefiore than patients in the other arm. Second, as our main data source is the EHR, we do not have information on whether prescriptions were actually dispensed and our outcome measures are limited to those recorded in the course of routine clinical care. To address this limitation, we are planning to conduct a telephone survey of patients to understand patient-reported outcomes such as pain, functioning and patient satisfaction.

\section{Ethics and dissemination}

This trial was approved by the Montefiore Medical Center/Albert Einstein College of Medicine Institutional Review Board (IRB number: 2016-6036). This trial was also granted a waiver of informed consent, similar to previous studies of EHR-based provider interventions. ${ }^{41}{ }^{42}$ During data collection and analysis, all data collected for this study will be deidentified at the earliest possible opportunity and stored in an encrypted and password-protected database. At the conclusion of the trial, we will investigate the feasibility of depositing deidentified data in a publicly accessible repository that maintains confidentiality.

We will disseminate the results of this study through peer-reviewed publications, presentations at scientific conferences, and meetings with key stakeholders including health system leadership. Reporting of results will be in accordance with the Consolidated Standards of Reporting Trials extension to cluster randomised trials. ${ }^{43}$

\section{Author affiliations}

${ }^{1}$ Division of General Internal Medicine, Montefiore Medical Center/Albert Einstein College of Medicine, New York City, New York, USA

${ }^{2}$ Institute for Implementation Science in Population Health, City University of New York (CUNY), New York City, New York, USA

${ }^{3}$ Department of Epidemiology and Biostatistics, School of Public Health, City University of New York (CUNY), New York City, New York, USA

${ }^{4}$ Division of Hospital Medicine, Montefiore Medical Center/Albert Einstein College of Medicine, New York City, New York, USA

${ }^{5}$ Department of Epidemiology and Population Health, Montefiore Medical Center/ Albert Einstein College of Medicine, New York City, New York, USA

${ }^{6}$ Montefiore Information Technology, Montefiore Medical Center, New York City, New York, USA

Contributors $\mathrm{MBa}$ is the principal investigator of this trial and led its conception and design. DN, MH, WS and CC supervised the study design and all authors (MBa, $\mathrm{DN}, \mathrm{MH}, \mathrm{WS}, \mathrm{MS}, \mathrm{MBe}$ and $\mathrm{CC}$ ) made substantial contributions to the conception and design of this work. MBa drafted the manuscript and all authors (MBa, DN, MH, WS, MS, MBe and CC) revised it for critically important intellectual content. All authors (MBa, DN, MH, WS, MS, MBe and CC) provided final approval of the manuscript.

Funding This study is supported by the National Institute on Drug Abuse (K08DA043050) and the National Center for Advancing Translational Sciences (CTSA Grant UL1TR001073) of the National Institutes of Health. CC is also supported by the National Institute on Drug Abuse (K24DA036955). CC and DN are supported by the National Institute of Allergy and Infectious Diseases of the National Institutes of Health (P30Al124414).

Disclaimer The content is solely the responsibility of the authors and does not necessarily represent the official views of the National Institutes of Health. The funding agency has no role in design or conduct of the study or the decision to publish study results.

Competing interests None declared.

Patient consent Not required.

Ethics approval The Montefiore Medical Center/Albert Einstein College of Medicine Institutional Review Board.

Provenance and peer review Not commissioned; externally peer reviewed.

Open Access This is an Open Access article distributed in accordance with the Creative Commons Attribution Non Commercial (CC BY-NC 4.0) license, which permits others to distribute, remix, adapt, build upon this work non-commercially, and license their derivative works on different terms, provided the original work is properly cited and the use is non-commercial. See: http://creativecommons.org/ licenses/by-nc/4.0/

(c) Article author(s) (or their employer(s) unless otherwise stated in the text of the article) 2018. All rights reserved. No commercial use is permitted unless otherwise expressly granted.

\section{REFERENCES}

1. Guy GP, Zhang K, Bohm MK, et al. Vital Signs: Changes in Opioid Prescribing in the United States, 2006-2015. MMWR Morb Mortal Wkly Rep 2017;66:697-704.

2. Rudd RA, Seth P, David F, et al. Increases in Drug and OpioidInvolved Overdose Deaths - United States, 2010-2015. MMWR Morb Mortal Wkly Rep 2016;65:1445-52.

3. Florence CS, Zhou C, Luo F, et al. The Economic Burden of Prescription Opioid Overdose, Abuse, and Dependence in the United States, 2013. Med Care 2016;54:901-6.

4. Bohnert AS, Valenstein M, Bair MJ, et al. Association between opioid prescribing patterns and opioid overdose-related deaths. JAMA 2011;305:1315-21. 
5. Fulton-Kehoe D, Sullivan MD, Turner JA, et al. Opioid poisonings in Washington State Medicaid: trends, dosing, and guidelines. Med Care 2015;53:679-85.

6. Lewis ET, Cucciare MA, Trafton JA. What do patients do with unused opioid medications? Clin J Pain 2014;30:654-62.

7. Centers for Disease Control and Prevention (CDC). Adult use of prescription opioid pain medications - Utah, 2008. MMWR Morb Mortal Wkly Rep 2010;59:153-7.

8. Kennedy-Hendricks A, Gielen A, McDonald E, et al. Medication sharing, storage, and disposal practices for opioid medications among US Adults. JAMA Intern Med 2016;176:1027-9.

9. McCabe SE, West BT, Boyd CJ. Leftover prescription opioids and nonmedical use among high school seniors: a multi-cohort national study. J Adolesc Health 2013;52:480-5.

10. Hall AJ, Logan JE, Toblin RL, et al. Patterns of abuse among unintentional pharmaceutical overdose fatalities. JAMA 2008;300:2613-20.

11. Center for Behavioral Health Statistics and Quality. Behavioral health trends in the United States: Results from the 2014 National Survey on Drug Use and Health (HHS Publication No. SMA 15-4927, NSDUH Series H-50). Rockville, MD, 2015.

12. Voepel-Lewis T, Wagner D, Tait AR. Leftover prescription opioids after minor procedures: an unwitting source for accidental overdose in children. JAMA Pediatr 2015;169:497-8.

13. Bailey JE, Campagna E, Dart RC; RADARS System Poison Center Investigators. The underrecognized toll of prescription opioid abuse on young children. Ann Emerg Med 2009;53:419-24.

14. National Conference of State Legislatures. Prescribing Policies: States Confront Opioid Overdose Epidemic. http://www.webcitation. org/6wqUxdaQp (accessed 29 Jan 2018).

15. Johnson EJ, Goldstein D. Do Defaults save lives? Science 2003;302:1338-9.

16. Patel MS, Day S, Small DS, et al. Using default options within the electronic health record to increase the prescribing of genericequivalent medications: a quasi-experimental study. Ann Intern Med 2014;161(10 Suppl):S44-S52

17. Zwank MD, Kennedy SM, Stuck LH, et al. Removing default dispense quantity from opioid prescriptions in the electronic medical record. Am J Emerg Med 2017;35:1567-9.

18. Von Korff M, Korff MV, Saunders K, et al. De facto long-term opioid therapy for noncancer pain. Clin J Pain 2008;24:521-7.

19. Hooten WM, St Sauver JL, McGree ME, et al. Incidence and Risk Factors for Progression From Short-term to Episodic or Long-term Opioid Prescribing: A Population-Based Study. Mayo Clin Proc 2015:90:850-6.

20. Cantrill SV, Brown MD, Carlisle RJ, et al. Clinical policy: critical issues in the prescribing of opioids for adult patients in the emergency department. Ann Emerg Med 2012;60:499-525.

21. Epstein $\mathrm{H}$, Hansen $\mathrm{C}$, Thorson D. A protocol for addressing acute pain and prescribing opioids. Minn Med 2014;97:47-51.

22. Chou R, Qaseem A, Snow V, et al. Diagnosis and treatment of low back pain: a joint clinical practice guideline from the American College of Physicians and the American Pain Society. Ann Intern Med 2007;147:478-91.

23. Harris K, Curtis J, Larsen B, et al. Opioid pain medication use after dermatologic surgery: a prospective observational study of 212 dermatologic surgery patients. JAMA Dermatol 2013;149:317-21.

24. Bates C, Laciak R, Southwick A, et al. Overprescription of postoperative narcotics: a look at postoperative pain medication delivery, consumption and disposal in urological practice. J Urol 2011;185:551-5.

25. Maughan BC, Hersh EV, Shofer FS, et al. Unused opioid analgesics and drug disposal following outpatient dental surgery: A randomized controlled trial. Drug Alcohol Depend 2016;168:328-34.

26. Paulozzi LJ, Strickler GK, Kreiner PW, et al. Controlled Substance Prescribing Patterns-Prescription Behavior Surveillance System, Eight States, 2013. MMWR Surveill Summ 2015;64:1-14.

27. Bohnert AS, Logan JE, Ganoczy D, et al. A detailed exploration into the association of prescribed opioid dosage and overdose deaths among patients with chronic pain. Med Care 2016;54:435-41.

28. Dunn KM, Saunders KW, Rutter CM, et al. Opioid prescriptions for chronic pain and overdose: a cohort study. Ann Intern Med 2010;152:85-92.

29. U.S. Department Of Health And Human Services. National pain strategy: a comprehensive population health-level strategy for pain. Washington, DC, 2016.

30. Healthcare Cost and Utilization Project (HCUP). Beta clinical classifications software (CCS) for ICD-10-CM/PCS. http://www. hcup-us.ahrq.gov/toolssoftware/ccs10/ccs10.jsp (accessed 29 Jan 2018).

31. Donner A, Klar N. Pitfalls of and controversies in cluster randomization trials. Am J Public Health 2004;94:416-22.

32. Randolph AG, Haynes RB, Wyatt JC, et al. Users' Guides to the Medical Literature: XVIII. How to use an article evaluating the clinical impact of a computer-based clinical decision support system. JAMA 1999;282:67-74.

33. Tunis SR, Stryer DB, Clancy CM. Practical clinical trials: increasing the value of clinical research for decision making in clinical and health policy. JAMA 2003;290:1624-32.

34. Greevy R, Lu B, Silber JH, et al. Optimal multivariate matching before randomization. Biostatistics 2004;5:263-75.

35. Meyer BD. Natural and quasi-experiments in economics. Journal of Business \& Economic Statistics 1995;13:151-61.

36. Angrist J, Pischke J. Mostly harmless econometrics: an empiricist's companion. Princeton, NJ: Princeton University Press, 2009.

37. Ryan AM, Burgess JF, Dimick JB. Why we should not be indifferent to specification choices for difference-in-differences. Health Serv Res 2015;50:1211-35.

38. Huber PJ. The behavior of maximum likelihood estimates under nonstandard conditions. Proc Fifth Berkeley Symp Math Statist Prob 1967;1:221-3.

39. White $\mathrm{H}$. A heteroskedasticity-consistent covariance matrix estimator and a direct test for heteroskedasticity. Econometrica 1980;48:817-38.

40. Fazzari MJ, Kim MY, Heo M. Sample size determination for threelevel randomized clinical trials with randomization at the first or second level. J Biopharm Stat 2014;24:579-99.

41. Linder JA, Rigotti NA, Schneider LI, et al. An electronic health record-based intervention to improve tobacco treatment in primary care: a cluster-randomized controlled trial. Arch Intern Med 2009;169:781-7.

42. Sequist TD, Gandhi TK, Karson AS, et al. A randomized trial of electronic clinical reminders to improve quality of care for diabetes and coronary artery disease. J Am Med Inform Assoc 2005;12:431-7.

43. Campbell MK, Piaggio G, Elbourne DR, et al. Consort 2010 statement: extension to cluster randomised trials. BMJ 2012;345:e5661. 